\title{
Os três momentos pedagógicos e o contexto de produção do livro "Física"*
}

\author{
The three pedagogical moments \\ and the production context of the book named Física
}

\author{
Cristiane Muenchen ${ }^{1}$. Demétrio Delizoicov ${ }^{2}$
}

\begin{abstract}
Resumo: Com a publicação, no final dos anos 1980, dos livros Metodologia do Ensino de Ciências, e Física, a dinâmica conhecida como Três Momentos Pedagógicos (3MP) passou a ser disseminada. Ambas as obras se inserem na Coleção Magistério $-2^{\circ}$ grau, que é resultado do "Projeto diretrizes gerais para o ensino de $2^{\circ}$ grau: núcleo comum e habilitação magistério". É no decorrer desse projeto que ocorre interação entre o grupo de pesquisadores que implementou a perspectiva freireana no contexto da educação escolar e educadores alinhados com a perspectiva crítico-social dos conteúdos, que conceberam o desenvolvimento da Coleção Magistério $2^{\circ}$ grau. Esse contexto de interação é objeto de investigação no presente artigo, a partir da análise de como os 3MP foram abordados na obra Física.
\end{abstract}

Palavras-chave: Três Momentos Pedagógicos. Ensino de Física. Metodologia.

\begin{abstract}
With the publication in late 1980 of the books that have as titles Metodologia do Ensino de Ciências and Física, the dynamics known as Three Pedagogical Moments (3PM) has become widespread. Both works are inserted in a Collection of Books for the High School (Coleção Magistério - $2^{\circ}$ grau), which results from a project named "Diretrizes Gerais para o ensino de $2^{\circ}$ grau: Núcleo Comum e Habilitação Magistério". During this project, the interaction between the group of researchers that implemented the Freirean perspective in the context of school education, ie, authors of the books Metodologia do Ensino de Ciências and Física, and educators in line with the critical-social perspective of the content, who designed the development of the collection Magistério $-2^{\circ}$ grau - for teacher education occurs. This context of interaction is investigated in this article, based on an analysis of how the 3PM were addressed in the book Física.
\end{abstract}

Keywords: Three Pedagogical Moments. Physics teaching. Methodology.

\footnotetext{
*Uma versão preliminar dessa pesquisa intitulada "Os três momentos pedagógicos e o contexto de produção do livro Física" foi apresentada no XIX Simpósio Nacional de Ensino de Física (SNEF), realizado de 30 de janeiro a 04 de fevereiro de 2011, em Manaus, AM. O livro "Física" refere-se à publicação de Angotti e Delizoicov (1990).

${ }^{1}$ Departamento de Física, Universidade Federal de Santa Maria (UFSM), Avenida Roraima, n. 1000, Camobi, CEP 97105-900, Santa Maria, RS, Brasil. E-mail: <crismuenchen@yahoo.com.br>

${ }^{2}$ Departamento de Metodologia de Ensino, Centro de Ciências da Educação, Universidade Federal de Santa Catarina (UFSC), Florianópolis, SC, Brasil.
} 


\section{Introdução}

No período de 1985-1988, a Coordenadoria para Articulação com Estados e Municípios da Secretaria do Ensino de $2^{\circ}$ Grau do MEC, com apoio administrativo da Pontifícia Universidade Católica de São Paulo, propôs e desenvolveu o "Projeto diretrizes gerais para o ensino de $2^{\circ}$ grau: núcleo comum e habilitação magistério”. Pimenta e Gonçalves (1990, p. 22), ao resgatarem o histórico deste projeto, destacam: “[...] o presente projeto levou à produção de [...] subsídios para o desenvolvimento de conteúdos das disciplinas do Núcleo Comum e da Habilitação Magistério (24 documentos)".

Os subsídios referidos originaram os livros da denominada Coleção Magistério $-2^{\circ}$ grau, que foram publicados a partir do final dos anos 1980. Publicado, em primeira edição em 1990, o livro Física (DELIZOICOV; ANGOTTI, 1990a) constituiu a série Formação Geral, que subsidiava o ensino das disciplinas do Núcleo Comum; e o livro "Metodologia do Ensino de Ciências" (DELIZOICOV; ANGOTTI, 1990b), a série Formação do Professor, que subsidiava o ensino das disciplinas da Habilitação Magistério. Ambos os livros propunham e usaram a dinâmica didático-pedagógica, que ficou conhecida como os "Três Momentos Pedagógicos" (3MP), em sintonia com a perspectiva, do que, posteriormente, denominou-se, abordagem temática (DELIZOICOV; ANGOTTI; PERNAMBUCO, 2002).

A edição dos livros possibilitou a disseminação desta dinâmica, sobretudo devido aos seguintes motivos: (1) o livro "Física", por meio do Programa de Melhoria e Expansão do Ensino Médio (MEC) ${ }^{3}$, e o livro "Metodologia do Ensino de Ciências", que integrou o Programa Nacional Biblioteca do Professor (PNBP) do ano de $1994^{4}$; (2) os livros também constaram e constam como bibliografia em editais de concursos públicos, para a carreira do magistério, abertos por secretarias de educação, conforme pode-se verificar, por exemplo, por meio de levantamento na rede web, em sítio de busca. Foram encontradas diversas secretarias de educação que promoveram concursos de magistério, nas quais as obras "Física e Metodologia do Ensino de Ciências" constavam entre as referências bibliográficas destacadas. Dentre as secretarias, destacam-se: Caieiras (SP), Campo Limpo Paulista (SP), Resende (RJ), Osório (RS), Caxias do Sul (RS), Porto Alegre (RS), Belo Horizonte (MG), Lavínia (SP), Duque de Caxias (RJ), Aracruz (ES), Palhoça (SC) e Alegrete (RS); (3) uso, como bibliografia, em disciplinas de cursos de licenciatura da área de ciências da natureza e de programas de pós-graduação com foco no ensino de Ciências e em cursos de formação continuada de professores no quais os 3MP são empregados. Por intermédio de levantamento na rede web, foram encontradas diversas Instituições de Ensino Superior, nas quais as obras "Física" e "Metodologia do Ensino de Ciências" constavam entre as referências bibliográficas de disciplinas ministradas. Dentre as universidades, destacam-se: Universidade Federal de Santa Maria (UFSM), Universidade Federal de São Carlos (UFScar), Universidade de Brasília (UnB), Universidade Estadual Paulista

\footnotetext{
${ }^{3}$ Ver, por exemplo, $2^{\mathrm{a}}$ Edição Revista, $3^{\mathrm{a}}$ reimpressão, 2003, distribuição realizada pela Secretaria de Estado da Educação de São Paulo, com financiamento do Programa de Melhoria e Expansão do Ensino Médio (MEC). ${ }^{4}$ Conforme informações da Editora Cortez, o livro "Metodologia do ensino de ciências" foi adquirido pela FAE/ MEC no segundo semestre de 1994 e primeiro semestre de 1995. Foram distribuídos para cerca de 5.500 escolas e Secretarias Municipais de Educação de todos estados brasileiros.
} 
(Unesp), Universidade Federal de Sergipe (UFS), Universidade Federal de São João del-Rei (UFSJ), Universidade Federal de Mato Grosso do Sul (UFMS), Universidade Federal do Pará (UFPA), Centro Universitário Franciscano (INUFRA), Universidade Estadual do Oeste do Paraná (UNIOESTE) e Universidade Estadual de Maringá (UEM).

Com o intuito de averiguar o processo da pesquisa em ensino de Ciências na região central do RS, Muenchen e Delizoicov (2009) localizaram e analisaram a presença dos 3MP nos trabalhos apresentados pela região central do RS nos anais dos Encontros Nacionais de Pesquisa em Educação em Ciências (ENPEC) ${ }^{5}$. Nessa pesquisa, foi possível verificar que, no $1^{\circ}$ encontro, realizado em 1997, os dois trabalhos elencados por fazer referência aos 3MP apresentam, em suas referências bibliográficas, as obras citadas. Já no $5^{\circ}$ encontro, ocorrido em 2005, verificou-se que, dos onze trabalhos, nove trazem, em suas referências, os livros citados.

Além disso, Muenchen (2010), ao entrevistar formadores, constatou que as obras "Física" (DELIZOICOV; ANGOTTI, 1990a) e "Metodologia do Ensino de Ciências" (DELIZOICOV; ANGOTTI, 1990b) foram referências tanto para se entrar em contato com os $3 \mathrm{MP}$ como, efetivamente, utilizadas também no processo de disseminação dos $3 \mathrm{MP}$, durante o desenvolvimento das disciplinas em que esses formadores atuavam.

Também, o texto original, produzido no âmbito do "Projeto diretrizes gerais para o ensino de $2^{\circ}$ grau: núcleo comum e habilitação magistério", e que foi submetido à publicação do livro de Física, faz parte, atualmente, do elenco de obras do Portal Domínio Público, mantido pelo MEC, que disponibiliza uma biblioteca digital desenvolvida em software livre, na qual o texto integral pode ser obtido ${ }^{6}$.

As obras, portanto, parecem ter tido um papel central na forma de contato e compreensão sobre a dinâmica dos 3MP. Este artigo tem como foco uma análise da inserção da dinâmica dos 3MP no livro "Física", considerando que os autores precisaram realizar adequações relativamente à proposição inicial contida na concepção e uso dos 3MP, cuja origem localiza-se em outros projetos, conforme será resgatado no presente texto.

Delizoicov (2008) apresenta uma análise que tem como um dos focos as práticas pedagógicas que contribuíram para a construção e uso dos 3MP. Essas práticas foram desenvolvidas a partir de três projetos (DELIZOICOV, 1983; PERNAMBUCO et al.,1988; PONTUSCHKA, 1993; BRASIL, 1994, TORRES; O’CADIZ; WON, 2002) que articularam formação continuada de professores e a proposição de currículos e programas escolares. Os projetos tinham como um dos eixos estruturantes uma concepção curricular (DELIZOICOV, 2008) balizada por temas geradores (FREIRE, 1975) em sintonia com a perspectiva freireana da educação. Ainda que o livro "Física" já apresentasse a temática central "Produção, distribuição e consumo de energia elétrica" como estruturadora, tanto da organização da conceituação física como do desenvolvimento das atividades, estando em sintonia com a perspectiva de uma abordagem temática

\footnotetext{
${ }^{5}$ A opção por esse evento foi justificada pelo fato de concentrar, socializar e divulgar as pesquisas em educação em Ciências em áreas específicas como a Biologia, Química e Física. Além disso, de acordo com a autora, a maioria dos trabalhos apresentados no ENPEC reflete a produção dos programas de pós-graduação, representada, em grande parte, por meio das teses e dissertações defendidas.

${ }^{6}$ Disponível em: <http://www.dominiopublico.gov.br/pesquisa/DetalheObraForm.do?select_action=\&co_ obra $=28243>$. Acesso em: 18 jul. 2014.
} 
(DELIZOICOV; ANGOTTTI; PERNAMBUCO, 2002), o tema escolhido, conforme veremos nesse trabalho, não teve o caráter de um tema gerador, de acordo como o conceitua Freire (1975), e nem foi oriundo dos procedimentos analisados por Delizoicov (2008) e envolvidos na concepção de programas e currículos que tinham como meta o desafio da implementação da concepção curricular numa perspectiva freireana na educação escolar.

No entanto, ao proporem o desenvolvimento das atividades ao longo do livro, os autores sinalizavam alguma interlocução com conhecimentos prévios dos alunos sobre aspectos por eles vivenciados, conforme é explicitado na apresentação do livro:

Propomos um programa oriundo de uma temática central: produção, distribuição e consumo de energia elétrica. O professor poderá seguir as indicações, roteiros e instruções para o desenvolvimento do seu curso sem, contudo, deixar de introduzir elementos que interessam ao seu grupo de alunos, determinados pelas condições locais e regionais onde estejam atuando. (DELIZOICOV; ANGOT'TI, 1990a, p. 14)

Por sua vez, a intenção desta aproximação é observada na implementação da dinâmica dos 3MP, com a qual é organizado cada um dos 21 tópicos que estruturam o livro. No item "A organização do trabalho docente" (DELIZOICOV; ANGOTTI, 1990a), explicita-se:

Orientações ao professor: detalham indicações metodológicas para o desenvolvimento dos conteúdos a nível teórico e experimental. Essas indicações são pautadas por três momentos pedagógicos: problematização inicial, organização do conhecimento e aplicação do conhecimento. (DELIZOICOV; ANGOTTI, 1990a, p. 28)

Essa dinâmica, abordada, inicialmente, por Delizoicov (1982, 1983), ao promover a transposição da concepção de educação de Paulo Freire para o espaço da educação formal, pode ser assim caracterizada:

Problematização Inicial: apresentam-se questões ou situações reais que os alunos conhecem e presenciam e que estão envolvidas nos temas. Nesse momento pedagógico, os alunos são desafiados a expor o que pensam sobre as situações, a fim de que o professor possa ir conhecendo o que eles pensam. Para os autores, a finalidade desse momento é propiciar um distanciamento crítico do aluno ao se defrontar com as interpretações das situações propostas para discussão, e fazer com que ele sinta a necessidade da aquisição de outros conhecimentos que ainda não detém.

Organização do Conhecimento: momento em que, sob a orientação do professor, os conhecimentos de física necessários para a compreensão dos temas e da problematização inicial são estudados.

Aplicação do Conhecimento: momento que se destina a abordar sistematicamente o conhecimento incorporado pelo aluno, para analisar e interpretar tanto as situações iniciais que determinaram seu estudo quanto outras que, embora não estejam diretamente ligadas ao momento inicial, possam ser compreendidas pelo mesmo conhecimento. 
Pretende-se, então, caracterizar a trajetória de transformações ocorridas com a disseminação dos 3MP que vem ocorrendo desde 1982, particularmente as ocasionadas com a produção do livro "Física" de autoria de Delizoicov e Angotti (1990a).

\section{Um olhar para a compreensão das transformações}

Nessa pesquisa, procura-se caracterizar como os 3MP foram tratados na obra "Física". Trata-se, portanto, da análise de um processo de produção de conhecimentos pedagógicos. Com base em critérios histórico-epistemológicos de Ludwik Fleck, sobretudo por meio da categoria “circulação de ideias” (FLECK, 1986, 2010), realizou-se uma análise para a compreensão desse processo.

Ludwik Fleck desenvolveu sua reflexão epistemológica influenciado pela Escola Polonesa de Filosofia da Medicina (DA ROS, 2000; LÖWY, 1990). O livro "La génesis y el desarrollo de un hecho científico" (FLECK, 1986, 2010) foi escrito com o intuito de contrapor-se à concepção de Ciência do Círculo de Viena. O autor fez críticas ao empirismo lógico e sua produção é considerada contemporânea à de Popper e Bachelard, tendo sido publicada em alemão em 1935.

Suas ideias vêm sendo utilizadas de modo crescente no país. Levantamentos realizados por Lorenzetti (2008) indicam a existência de centros de estudos no Brasil que utilizam Fleck como referência, mostrando que sua obra e sua utilização em pesquisas nacionais apresentam uma trajetória e uma aplicação em diferentes contextos. Relativamente à pesquisa em Educação em Ciências (EC), são exemplos: Delizoicov et al. (2002) argumentam sobre a potencialidade das proposições de Fleck para fundamentar pesquisas em EC; Delizoicov, Carneiro e Delizoicov (2004) usam fundamentação baseada em Fleck ao realizar uma análise da constituição e produção da área de EC; Gonçalves, Marques e Delizoicov (2007) analisam a promoção do desenvolvimento profissional dos formadores de professores de Química com suporte em categorias epistemológicas fleckianas; Lorenzetti (2008), referenciando-se em Fleck, realiza uma análise epistemológica da produção de dissertações e teses sobre Educação Ambiental defendidas, entre 1981 e 2003, em programas de pós-graduação brasileiros; Slongo e Delizoicov (2010) fundamentam-se em Fleck para realizar uma análise epistemológica da produção de dissertações e teses de ensino de biologia defendidas entre 1972 e 2000 em programas de pós-graduação brasileiros.

Além deste uso, a perspectiva epistemológica de Fleck tem subsidiado análises sobre a produção de conhecimento ocorrida em episódios da história da ciência, tais como em: Delizoicov (2009), ao analisar aspectos relacionados à formulação da mecânica quântica; Scheid, Ferrari e Delizoicov (2005), ao considerarem as pesquisas que culminaram com a proposição do DNA; Delizoicov, Carneiro e Delizoicov (2004) e Delizoicov (2006), que analisam a origem do modelo da circulação sanguínea humana, e Leite, Ferrari e Delizoicov (2001), que têm como foco as leis de Mendel.

Fleck $(1986,2010)$ argumenta que o processo de conhecimento ocorre na interação do sujeito com o objeto, por meio da mediação do que ele denomina de estilo de pensamento (EP) e no interior de um coletivo de pensamento (CP). O estilo de pensamento é o direciona- 
dor do modo de pensar e de agir de um grupo de pesquisadores de uma determinada área do conhecimento. O coletivo de pensamento pode ser compreendido como uma comunidade de indivíduos que compartilham práticas, concepções, tradições e normas.

Na estrutura geral do CP, Fleck $(1986,2010)$ distingue os círculos esotérico e exotérico. A presença de um círculo esotérico, formado por especialistas de uma determinada área do conhecimento, caracteriza a identidade primeira do CP, por ser o portador do EP. É a partir desse núcleo de conhecimentos e de práticas compartilhadas que se forma o círculo exotérico, constituído pelos leigos formados, quando passam a interagir, por meio de múltiplas alternativas, com o círculo esotérico.

Entre os círculos exotérico e esotérico, são estabelecidas relações dinâmicas que contribuem para a ampliação e disseminação do conhecimento, denominadas: circulação intracoletiva e intercoletiva de ideias. A circulação intracoletiva ocorre entre membros pertencentes ao círculo esotérico de um mesmo CP. Por outro lado, a circulação intercoletiva ocorre entre os círculos esotérico e exotérico que compõem o CP. Fleck (1986) argumenta que uma mesma pessoa pode pertencer a mais de um coletivo de pensamento, inclusive, constituindo, eventualmente, parte do círculo esotérico de um CP e do círculo exotérico de outros coletivos. Esta característica pode, muitas vezes, ocasionar transformações em estilos de pensamento, quando, por meio da circulação intercoletiva de ideias, conhecimentos e práticas, mediada por problema não solucionado por um determinado EP. Este tipo de problema, que potencialmente leva à transformação do EP, Fleck $(1986,2010)$ denomina de complicação.

A seguir, são realizadas considerações, com base em critérios histórico-epistemológicos de Ludwik Fleck, a respeito de como os 3MP foram abordados na obra "Física". Com isso, pretende-se contribuir para uma compreensão da prática pedagógica de educadores que nela se referenciam, assim como para um resgate de aspectos que fundamentaram teórica e praticamente a gênese e proposição dos 3MP.

\section{Os Três Momentos Pedagógicos no livro Física}

O livro "Física" contém uma proposta de ensino de Física para o $2^{\circ}$ grau (atual Ensino Médio) que contempla aspectos metodológicos associados ao desenvolvimento dos conteúdos. Destina-se aos alunos de licenciatura em Física, que pretendem cursar a disciplina "Instrumentação para o ensino, metodologia e/ou prática de ensino", e aos professores de Física do $2^{\circ}$ grau (DELIZOICOV; ANGOTTI, 1990a).

Ao longo da elaboração da obra, a seguinte questão esteve presente: "Para que serve o ensino de Física no $2^{\circ}$ grau?" Com isso, os autores demonstram a preocupação em subsidiar um trabalho didático-pedagógico que permita tanto a apreensão dos conceitos, leis, relações da Física e sua utilização, assim como sua aproximação com fenômenos ligados a situações vividas pelos educandos (DELIZOICOV; ANGOTTI, 1990a).

Os autores destacam o mundo vivido, enfatizando que pretendem dar destaque ao ensino de Física independentemente de o aluno prosseguir ou não os estudos. Assim, torna-se difícil a utilização dessa proposta pelos professores que se preocupam exclusivamente em preparar os alunos para os exames futuros, como os vestibulares (DELIZOICOV; ANGOTTI, 1990a). 
Dentre os pressupostos para a elaboração do programa, estão os conceitos unificadores (ANGOTTI, 1994, p. 22), que "permitem perpassar as fronteiras rígidas impostas, sobretudo pelos livros didáticos, ao apresentarem os conteúdos de Física.”

Após a apresentação e discussão de algumas premissas epistemológicas e pedagógicas defendidas, os autores apresentam, ao educador, os 3MP, que, dentro de cada tópico, fazem parte do item "Orientações ao professor". Assim:

\section{Primeiro Momento: a problematização inicial}

Delizoicov e Angotti (1990a) comentam que, na problematização, são apresentadas questões e/ou situações para discussão com os alunos. Com relação à função do Primeiro Momento, enfatizam que:

Mais do que simples motivação para se introduzir um conteúdo específico, a problematização inicial visa à ligação desse conteúdo com situações reais que os alunos conhecem e presenciam, mas que não conseguem interpretar completa ou corretamente porque, provavelmente não dispõem de conhecimentos científicos suficientes. (DELIZOICOV; ANGOTTI, 1990a, p. 29)

O livro "Física" destaca a problematização que pode ocorrer, pelo menos, em dois sentidos. De um lado, estão as concepções alternativas dos alunos, aquilo de que o aluno já tem noções, fruto de aprendizagens anteriores. De outro, um problema a ser resolvido, quando o aluno deve sentir a necessidade de conhecimentos que ainda não possui.

Delizoicov e Angotti (1990a, p. 29) recomendam que a postura do educador, nesse momento, deve se voltar mais para "questionar e lançar dúvidas sobre o assunto que para responder e fornecer explicações". Explicam, ainda, que o critério para a escolha das questões "é o seu vínculo com o conteúdo a ser desenvolvido, ou seja, as questões devem estar necessariamente relacionadas com o conteúdo de Física do tópico ou unidade em estudo."

O trecho acima explicitado propiciou reflexões sobre o ato de problematizar o conteúdo. Assim, emergiu o contexto de produção da obra, que está relacionado com a interação com os críticos sociais do conteúdo (LIBÂNEO, 1987), como se verá no decorrer do artigo.

Comparando-se a função do Primeiro Momento, assim explicitada no livro, com a que teve na implementação dos projetos realizados na Guiné Bissau (ANGOTTI, 1982; DELIZOICOV, 1980, 1982, 1983), no Rio Grande do Norte (PERNAMBUCO, 1981; PERNAMBUCO et al., 1988) e no município de São Paulo (SÃO PAULO, 1990, 1992), destaca-se que não se explicita a relação que esse momento pedagógico possui com situações significativas envolvidas nos temas geradores, diferentemente do que é realizado nos projetos referidos. Neles as situações significativas, obtidas por meio da investigação temática (FREIRE, 1975), representam papel estruturador fundamental na implementação dos 3MP, conforme destaca Delizoicov (2008). Apesar de enfatizar a necessidade de um tratamento didático-pedagógico do conhecimento do aluno sobre situações reais que os alunos conhecem e presenciam, não estabelece critérios que 
possam contribuir para a seleção do que seriam e quais seriam as situações a que se referem. De fato, essa mudança na proposta de uso do Primeiro Momento parece estar relacionada às diferentes perspectivas didático-pedagógicas que embasam as proposições oriundas dos três projetos e a do projeto do qual o livro é parte constituinte (Coleção Magistério). Nessa coleção, conforme será aprofundado mais adiante, o princípio estruturante da organização e apresentação do conteúdo tem como referência básica os conceitos que compõem as várias disciplinas, ou seja, o que se denomina uma abordagem conceitual, segundo Delizoicov, Angotti e Pernambuco (2002). Já os três projetos anteriormente referidos têm, como referência básica, os temas geradores e os conceitos que estruturam as várias áreas do conhecimento, sendo a seleção desses conceitos, realizada por educadores, subordinada aos temas geradores, conforme explicam Delizoicov, Angotti e Pernambuco (2002).

\section{Segundo Momento: a organização do conhecimento}

Os autores explicam que, no segundo momento, os conhecimentos de Física necessários para a compreensão do tema e da problematização inicial serão sistematicamente estudados sob orientação do professor. Com relação ao núcleo do conteúdo específico de cada tópico, Delizoicov e Angotti (1990a, p. 30) afirmam que:

[...] será preparado e desenvolvido, durante o número de aulas necessárias, em função dos objetivos definidos e do livro didático ou outro recurso pelo qual o professor tenha optado para o seu curso. Serão ressaltados pontos importantes e sugeridas atividades, com as quais se poderá trabalhar para organizar a aprendizagem.

Do ponto de vista metodológico, para o desenvolvimento desse momento, o professor é aconselhado a utilizar as mais diversas atividades, como: exposição, formulação de questões, texto para discussões, trabalho extraclasse, revisão e destaque dos aspectos fundamentais, experiências.

\section{Terceiro Momento: a aplicação do conhecimento}

Ao apresentar esse momento pedagógico, os autores afirmam que:

Destina-se, sobretudo, a abordar sistematicamente o conhecimento que vem sendo incorporado pelo aluno, para analisar e interpretar tanto as situações iniciais que determinaram o seu estudo, como outras situações que não estejam diretamente ligadas ao motivo inicial, mas que são explicadas pelo mesmo conhecimento. (DELIZOICOV; ANGOT'TI, 1990a, p. 31)

Com isso, pretende-se que, "dinâmica e evolutivamente", o aluno perceba que o conhecimento, além de ser uma construção historicamente determinada, está acessível para qualquer cidadão e, por isso, deve ser apreendido, para que possa fazer uso dele. Desta forma, "pode-se evitar a excessiva dicotomização entre processo e produto, física de 'quadro-negro' e física da 'vida"' (DELIZOICOV; ANGOTTI, 1990a, p. 31). 


\section{Das interações entre os críticos sociais de conteúdo e freireanos}

Conforme destacado no primeiro momento pedagógico, os autores enfatizam que o critério para escolha das questões é o seu vínculo com o conteúdo a ser desenvolvido, ou seja, necessariamente relacionadas com o conteúdo de Física a ser estudado.

Essa transformação na proposição do Primeiro Momento pode estar relacionada às distintas perspectivas didático-pedagógicas que embasam as propostas dos projetos anteriormente desenvolvidos (BRASIL, 1994; DELIZOICOV, 1983; PERNAMBUCO et al., 1988; PONTUSCHKA, 1993) e a do projeto do qual o livro é parte constituinte, a Coleção Magistério.

A equipe responsável pela proposição e coordenação do "Projeto diretrizes gerais para o ensino de $2^{\circ}$ grau: núcleo comum e habilitação magistério" está em sintonia com a perspectiva adotada pela pedagogia progressista crítico-social dos conteúdos (LIBÂNEO, 1987). Assim, dentre as características e objetivos que constam na apresentação da coleção das séries, destacam-se:

O principal objetivo desta Coleção é contribuir para a melhoria da qualidade do ensino ministrado na escola de $2^{\circ}$ grau, [...] mediante livros didáticos com conteúdos pautados pelo seu caráter científico e sistemático, em estreita ligação com exigências metodológicas do ensino e aprendizagem.

$[\ldots]$

Cada um dos livros oferece a professores e alunos, além dos textos referentes às unidades do programa, um estudo sobre os objetivos da disciplina, uma proposta de conteúdos básicos e indicações metodológicas para o trabalho conjunto do professor e dos alunos [...]. (PIMENTA; LIBÂNEO, 1990, p. 10, grifos nossos)

Por outro lado, não foi encontrada menção a alguma articulação que poderia ser estabelecida entre conteúdos e temas. Parece que o termo tema, qualquer que seja o significado que possa ser a ele atribuido, não faz parte das considerações de Pimenta e Libâneo (1990) ao caracterizarem o "Projeto diretrizes gerais para o ensino de $2^{\circ}$ grau: núcleo comum e habilitação magistério". De fato, Libâneo (1987), ao se referir à perspectiva educacional freireana, denominando-a de tendência progressista libertadora, faz uma caracterização segundo a qual essa perspectiva não teria compromissos com a veiculação de conhecimentos universais, tais como os oriundos da Física. Ele afirma, sobre a tendência progressista libertadora:

Os conteúdos tradicionais são recusados porque cada pessoa, cada grupo envolvidos na ação pedagógica dispõem em sí próprios, ainda que de forma rudimentar, dos conteúdos necessários dos quais se parte. $\mathrm{O}$ importante não é a transmissão de conteúdo específicos, mas despertar uma nova forma da relação com a experiência vivida ... Se nisso consiste o conteúdo do trabalho educativo, dispensam-se um programa previamente estruturado, trabalhos escritos, aulas expositivas, assim como qualquer tipo de verificação direta da aprendizagem, formas próprias da 'educação bancária' [...]. (LIBÂNEO, 1987, p. 33-34) 
Parece, então, que, com esta interpretação do que seria a proposta freireana para estruturar o processo pedagógico e a elaboração de programas a partir de temas geradores, a conclusão imediata é que não caberia qualquer menção ao termo "tema", sobretudo ao tema gerador, enquanto estruturador de programas de ensino, uma vez que a meta do "Projeto diretrizes gerais para o ensino de $2^{\circ}$ grau: núcleo comum e habilitação magistério" corresponderia à implementação da proposição da tendência progressista crítico-social dos conteúdos, defendida por Libâneo (1987).

Neste sentido, podemos associar a proposição da tendência progressista crítico-social dos conteúdos ao que Delizoicov, Angotti e Pernambuco (2002) caracterizam como abordagem conceitual, ou seja, a que organiza os conteúdos disciplinares tendo como referência, única e exclusivamente, a estrutura conceitual da disciplina, ou área do conhecimento, da qual se parte para a elaboração dos programas de ensino. Essa abordagem diferencia-se, fundamentalmente, da abordagem temática conforme caracterizada pelos autores, e que tem como príncípio a proposição dos conteúdos de ensino a partir de uma articulação orgânica entre temas e estruturas conceituais das várias áreas do conhecimento que compõem o currículo escolar, ficando a seleção de conceitos científicos a serem incluídos nos programas de ensino subordinados à comprensão dos temas.

Assim, poderá ser observado que os demais livros da coleção, particularmente "Química" (BELTRAN; CISCATO, 1991) e "Biologia" (SONCINI; CASTILHO JR., 1991), mesmo introduzindo aspectos inovadores que os diferenciam dos livros didáticos editados até aquele período, apresentam uma organização dos conteúdos que tem como referência a estrutura conceitual das suas respectivas áreas, em sintonia com o ideário do projeto, cuja concepção se afinava com a proposta da tendência crítico-social dos conteúdos. Nota-se, ainda, que o próprio livro "Metodologia de ensino de ciências", de Delizoicov e Angotti (1990b), com a colaboração dos autores dos livros "Química" e "Biologia", sequer menciona o termo tema e a possibilidade de um trabalho didático pedagógico que estabeleça alguma articulação entre temas e conceituação científica.

Não obstante isso, é introduzida a dinâmica dos 3MP, no livro "Metodologia de ensino de ciências", ao propor uma metodologia para o ensino de ciências, cuja proposição e construção teve origem nos projetos que implementaram a perspectiva freireana na educação escolar. No entanto, a proposição dos 3MP neste livro foi adequada às intenções do "Projeto diretrizes gerais para o ensino de $2^{\circ}$ grau: núcleo comum e habilitação magistério", conforme pode ser constatado no tópico 1, da unidade 3, que exemplifica o seu emprego em uma atividade cujo título é "Radiação solar: uma abordagem metodológica". Em síntese, articula uma dinâmica didática, que se baseia nos 3MP, para abordar o conceito científico de radiação e de radiação solar. De modo semelhante, e introduzindo outros parâmetros, que não os 3MP, para a abordagem dos conteúdos, os demais tópicos dessa unidade também exemplificam possibilidades para um procedimento didático de sala de aula para o ensino de biologia e química, respectivamente, organizados para abordarem os conceitos de fotossíntese e de combustão, conforme indicam os títulos dos tópicos, "Fotossíntese, uma abordagem metodológica" e "Combustão - duas interpretações diferentes", respectivamente.

Contudo, é fundamental considerar que, particularmente em relação à abordagem temática freireana, os temas geradores são obtidos por meio de um processo que Freire (1975) denomina de investigação temática, e a seleção de conceitos é realizada na etapa dessa investiga- 
ção denominada de redução temática, tendo como referência estruturas conceituais específicas oriundas das várias áreas dos conhecimentos universais. Delizoicov (2008) analisa o papel que a investigação temática e a redução temática tiveram na proposição de currículos e programas escolares durante a implantação dos três projetos citados, que tiveram como referência a perspectiva de Paulo Freire.

Destaca-se, portanto, o equívoco cometido por Libâneo (1987) ao supor que a abordagem de temas na concepção freireana seria a negação do ensino de conceituação específica oriunda de conhecimentos universais. Provavelmente, este equívoco pode ter sido ocasionado por neglicenciar o papel da investigação temática e da reducão temática nas proposições de Freire, ao qual o educador dedica quase todo o capítulo III do livro "Pedagogia do oprimido". Delizoicov (1991, p. 147) aponta este equívoco, afirmando:

De fato, a redução temática, quando negligenciada, leva a uma interpretação no mínimo distorcida do que é proposto por Freire. Ainda que toda a sua obra constitua um "relatório" da sua prática, como o próprio educador a ela se refere, prática advinda da atuação na educação (informal) de adultos, nela podemos encontrar indicações metodológicas e procedimentos que permitem, devidamente interpretados, orientar o trabalho educativo na escola pública e inclusive estruturar previamente um conteúdo (universal) programático.

Por sua vez Freire (2006, p. 44-45), quando secretário de educação da cidade de São Paulo, em entrevista ao jornal "Psicologia", assim se pronunciou relativamente às críticas, afirmando que não há

prática educativa sem conteúdo, quer dizer sem objeto de conhecimento a ser ensinado pelo educador e apreendido, para poder ser aprendido pelo educando. Isto porque a prática educativa é naturalmente gnosiológica e não é possível conhecer nada a não ser que nada se substantive e vire objeto a ser conhecido, portanto vire conteúdo. A questão fundamental é política. Tem que ver com: que conteúdos ensinar, a quem e a favor de que e de quem, contra quê, como ensinar. Tem que ver com quem decide sobre que conteúdos ensinar, que participação têm os estudantes, os pais, os professores, os movimentos populares na discussão em torno da organização dos conteúdos programáticos.

De acordo com Delizoicov, Angotti e Pernambuco (2002), o aspecto mais significativo da proposta de transposição da perspectiva freireana para a educação escolar é o currículo escolar. A estruturação das atividades educativas, incluindo a seleção de conteúdos, rompe com o tradicional paradigma curricular, baseado, exclusivamente, na abordagem conceitual.

Para Delizoicov, Angotti e Pernambuco (2002, p. 189), a abordagem temática constitui-se em: "Perspectiva curricular cuja lógica de organização é estruturada com base em temas com os quais são selecionados os conteúdos de ensino das disciplinas. Nessa abordagem, a conceituação científica da programação é subordinada ao tema”. 
Já a abordagem conceitual é vista como uma "perspectiva curricular cuja lógica de organização é estruturada pelos conceitos científicos, com base nos quais se selecionam os conteúdos de ensino" (DELIZOICOV; ANGOTTI; PERNAMBUCO, 2002, p. 190).

Percebe-se que, de acordo com os autores, a abordagem conceitual, ao propor e estruturar o programa de ensino, dá ênfase apenas à conceituação científica, enquanto a abordagem temática não se limita a esta exclusividade na estruturação do programa, ou seja, dá ênfase aos conceitos científicos como meio para a compreensão de um tema.

Deste modo, o livro "Física" procura incrementar uma proposta que tem como premissa uma estruturação que articula a temática central "produção, distribuição e consumo de energia elétrica" e conceituação física pertinente, que propiciaria uma compreensão oriunda da estrutura conceitual do conhecimento produzido pela Física, conforme representado no mapa temático-conceitual do livro. Por sua vez, a estrutura dos conteúdos programáticos, assim propostos, incluem processos relacionados à produção, distribuição e consumo de energia elétrica e a conceituação científica que permite uma compreensão destes processos. O próprio título de cada uma das seis unidades com as quais a conceituação científica é apresentada, e os respectivos tópicos com as quais cada uma é desenvolvida, reflete esta preocupação na articulação temas-conceitos. Assim, os títulos das seis unidades, de acordo com a Ementa do Programa (DELIZOICOV; ANGOTTI, 1990a, p. 21), são, respectivamente: “Queda-d'água; Roda-d'água; Ciclo da água; Energia elétrica; Geradores e dínamos; Transporte de energia"; e os títulos dos tópicos, num total de 21, expressam conceituação física como, por exemplo: Massa, peso e campo gravitacional; rotações; radiação solar; modelo microscópico; indução eletromagnética; Energia, matéria e ondas.

Moreira (2000), referindo-se às propostas curriculares contidas na pedagogia críticosocial dos conteúdos e na perspectiva freireana, argumentando que procuraram caminhar na contramão do discurso oficial hegemônico, destaca que essas duas tendências divergiam radicalmente em relação ao conteúdo a ser ensinado na escola. Ao comentar sobre as propostas de renovação curricular da pedagogia crítico-social dos conteúdos, o autor destaca que:

Não foi, então, na proposição de novas grades curriculares ou no esforço por integrar conteúdos de diferentes disciplinas que se concentraram as preocupações das reformulações curriculares pautadas na pedagogia dos conteúdos [...] A organização disciplinar foi mantida, em sintonia com a pedagogia dos conteúdos, cuja influência foi, mais uma vez, óbvia. Priorizou-se a seqüência lógica dos conteúdos de cada disciplina, de modo a ressaltar o que fosse essencial. (MOREIRA, 2000, p. 112-113)

Já ao explanar sobre a perspectiva freireana, o autor ressalta:

Os currículos pautados nos princípios de Freire deveriam ter como eixo organizador as necessidades e as exigências da vida social, não as disciplinas tradicionais. Daí a preocupação em codificar e decodificar temas geradores, trabalhados nas salas de aula por meio do diálogo entre professores e estudantes. (MOREIRA, 2000, p. 114) 
Podemos interpretar que as distintas formas de interação propiciadas pela coordenação do "Projeto diretrizes gerais para o ensino de $2^{\circ}$ grau: núcleo comum e habilitação magistério" entre a equipe do projeto possibilitaram uma circulação intercoletiva de ideias (FLECK, 1986, 2010). Durante a realização do projeto, ocorreu um trabalho conjunto entre, pelo menos, dois grupos de educadores que possuem ideias, conhecimentos e práticas pedagógicas distintas na implementação de currículos e programas escolares, ou seja, os críticos-sociais do conteúdo e os que se afinavam com a perspectiva freireana. Esta circulação intercoletiva teve, como um dos desdobramentos, as alterações evidenciadas na proposição do uso dos 3MP pelos autores do livro "Física".

Originalmente, os momentos pedagógicos instrumentalizavam uma prática pedagógica de sala de aula cuja finalidade era a de estruturar abordagens de conceitos científicos necessários para a compreensão de temas geradores, obtidos com a investigação temática. Delizoicov (2008, p. 56-57), quando se refere aos $3 \mathrm{MP}$, na análise que realizou sobre os três projetos que tiveram como meta a implementação da concepção freireana em rede públicas de ensino, destaca:

[...] a dinâmica de interações que pode ser planejada propicia a inclusão de elementos que podem potencializar desequilíbrios de certezas dos alunos, desestabilizações de modelos explicativos e consciência de lacunas e de necessidades cognitivas. Por outro lado, o uso mecânico destes momentos como um "método de ensino" para organizar as aulas de modo que o primeiro momento seja um simples pretexto, e justificativa, para se introduzir conceituação científica a ser abordada no segundo momento tem sido um dos problemas que demandam efetivo empenho e cuidados das equipes de formadores de professores na implementação das práticas freireanas. É fundamental a presença constante e sistematizada de dados obtidos na investigação temática para que, a partir deles, sejam sistemáticas as problematizações das "falas" dos alunos.

Esse é o principal aspecto que diferencia esta proposição daquela da pedagogia críticosocial dos conteúdos, já que não é seu pressuposto a estruturação dos programas de ensino a partir de temas geradores. Assim, as críticas e interpretações dos representantes da pedagogia progressista crítico-social dos conteúdos, com relação à tendência progressista libertadora, podem ter tido alguma influência no sentido de compreender os silêncios dos autores com relação aos aspectos mais característicos de uma abordagem temática freireana.

Entende-se que a obra "Física" se situa em outra perspectiva, em termos de concepções educacionais e curriculares, diferentes daquelas apresentadas em "Metodologia do ensino de ciências". Os autores propõem, no livro "Física", um programa que tem origem em uma temática central, que é a "Produção, distribuição e consumo de energia elétrica". O professor pode seguir as orientações e instruções propostas, porém, sem deixar de introduzir elementos relacionados às condições locais e regionais do local que esteja atuando. Essa temática central possibilita, de acordo com os autores, uma conexão entre o conhecimento em Física e as situações de relevância social, reais, concretas e vividas, considerando que "produção, distribuição e consumo de energia elétrica" estão relacionados a temas mais específicos, como a "radiação solar", e outros mais amplos, como as "transformações de energia pela natureza e pelo homem" (DELIZOICOV; ANGOTTI, 1990a). 
É possível que possa ter ocorrido uma autonomia relativamente maior dos autores na proposição e elaboração do livro "Física", no que diz respeito à implementação da abordagem temática. Mesmo que o tema "Produção, distribuição e consumo de energia elétrica" não tenha sido eleito a partir de uma investigação temática (DELIZOICOV, 2008; FREIRE, 1975) e, portanto, não possa ser confundido com um tema gerador, foi o que possibilitou a seleção e a estruturação da conceituação física desenvolvida no livro para sua compreensão. É notável que a seleção dos conceitos realizada exigiu a inclusão de conceitos relativos à Física Moderna que, na época, não faziam parte dos programas de física para o Ensino Médio, mas que, não obstante, se mostram como necessários para uma comprensão do tema da produção, distribuição e consumo de energia elétrica, pelo menos na estruturação dos conceitos específicos proposta pelos autores.

Deste modo, a circulação intercoletiva de ideias (FLECK, 1986), assim caracterizada no caso da produção do livro "Física", teve como desdobramento uma concepção mais focada no mundo vivido do educando e que se origina de uma temática central, ao invés de ter como premissa apenas a estrutura conceitual da Física. Ou seja, o texto não foi estruturado a partir da perspectiva de uma abordagem conceitual, ainda que os conceitos científicos, sobretudo da Física, estejam presentes e sejam abordados ao longo das atividades propostas.

A dinâmica de circulação intercoletiva de ideias (FLECK, 1986) auxilia a compreender a interação entre os dois grupos envolvidos no projeto Coleção Magistério. Para esse epistemólogo, a intensidade da circulação intercoletiva de ideias está relacionada com as possíveis diferenças e proximidades entre os estilos de pensamento de cada coletivo. Assim, pode-se afirmar que as concepções/ideias mais próximas entre dois coletivos favorecem a circulação intercoletiva de ideias. Nesse sentido, a aproximação dos autores das obras (freireanos - tendência progressista libertadora) com aspectos do ideário da proposta dos educadores da tendência crítico-social dos conteúdos, pode ter flexibilizado a coerção de pensamento (FLECK, 1986, 2010) advinda da constituição do coletivo de pensamento, assim como da constituição das ideias, conhecimentos e práticas, de modo a se produzir o livro com a proposição das alterações identificadas no papel dos $3 \mathrm{MP}$.

\section{Das interações dos autores com o grupo GREF}

Além da circulação intercoletiva de ideias, conhecimentos e práticas que ocorreram no âmbito do "Projeto diretrizes gerais para o ensino de $2^{\circ}$ grau: núcleo comum e habilitação magistério", entre os autores do livro "Física" e membros componentes do coletivo organizado em torno da concepção crítico-social dos conteúdos, é notável a circulação de ideias oriundas da interação dos autores com o Grupo de Reelaboração do Ensino de Física (GREF) ${ }^{7}$, constituído por um grupo de professores da rede estadual de ensino de São Paulo, coordenados por docentes do Instituto de Física da Universidade de São Paulo (USP).

\footnotetext{
${ }^{7}$ O GREF elaborou e utilizou uma proposta de ensino de Física para o Ensino Médio que se propunha vincular conceituação da Física à "experiência cotidiana dos alunos, procurando apresentar a eles a Física como instrumento de melhor compreensão e atuação na realidade". Disponível em: < http://www.if.usp.br/gref/>. Acesso em: 18 jul. 2014.
} 
Este grupo iniciou a sua atividade em 1984 e, além de formação continuada de professores, elaborou três textos (GRUPO DE REELABORAÇÃO DO ENSINO DE FÍSICA, 1990, 1992, 1995) destinados aos professores de física do Ensino Médio e, posteriormente, produziu textos ${ }^{8}$ para alunos. Menezes (1988) caracteriza a interação ocorrida com os autores do livro "Física" e explicita algumas das relações que se encontram na gênese das concepções e das produções tanto do livro como do projeto (MENEZES, 1996). Apesar de relativamente longa, a seguinte citação registra um depoimento histórico de Menezes (1996, p. 638-640) sobre as interações mencionadas e ocorridas há quase quarenta anos:

Há vinte anos em São Paulo, um grupo de Físicos - entre os docentes, João Zanetic, eu e, no início, Amélia Império Hamburquer e entre os pósgraduandos, Demétrio Delizoicov, José André Angotti e, no início, Mário Tekeia - começou a discutir uma metodologia de inspiração freireana para tentar transformar o ensino escolar da física, tradicionalmente formal e propedêutico. Paulo Freire ainda vivia seu exílio e eu voltara havia pouco da Alemanha, onde tinha entrado em contato com o "Pëdagogik der Unterdrückten”, título da edição alemã da Pedagogia do Oprimido. A ciência compreendida como elemento de emancipação, de formação da cidadania, era o que nos aproximava de suas ideias [...]. Os anos na Guiné-Bissau foram relatados e analisados nos trabalhos de mestrado de D. Delizoicov (1982) e de J. A. Angotti (1982), que também fizeram no Instituto de Física da USP (IFUSP) seus doutoramentos (1991). [...]. O trabalho na Guiné, que fez de ex-guerrilheiros professores, teve um seu similar no Rio Grande do Norte, onde as físicas Marta Pernambuco e Maria Cristina Dal Pian desenvolveram um projeto de educação comunitária em torno da problemática nordestina da água e da seca, ambas docentes da Universidade Federal do Rio Grande do Norte. Na época, o trabalho mencionado foi feito em São Paulo do Potengi, na periferia de Natal. A problematização, os temas geradores, enfim todo o arsenal freireano foi retrabalhado em estratégias específicas, foi aparelhado e reinventado para uma aplicação regular no ensino de ciências de uma escola oficial. [...] Em 1984, o Grupo de Reelaboração do Ensino de Física, o GREF, surgiu de uma iniciativa conjunta de professores da escola pública e de docentes universitários: Yassuko Hosoume, que tem coordenado o GREF, João Zanetic e eu éramos os docentes. Entre os professores secundaristas do grupo inicial, vários fizeram dissertações de mestrado com fundamentações ou referências freireanas, como Maria Lúcia Ambrósio (IFUSP, 1990), Maria Sumiê Watanabe Sátiro (IFUSP, 1989) e Rubens Barbosa de Camargo (UNICAMP, 1989). Este grupo não formalizou Freire como referência central, mas foi quem pela primeira vez, para o ensino de uma ciência específica, de fato adotou uma

${ }^{8}$ Disponível em: <http://www.if.usp.br/gref/pagina01.html>. Acesso em: 18 jul. 2014. 
prática dialógica e desenvolveu uma metodologia correspondente que tentarei brevemente descrever.

O professor conduz com seus alunos um levantamento de temas de interesse ou relevância para eles, que tenham proximidade com a disciplina da física prevista para a série e nível da turma, num procedimento que, naturalmente, já reflete a vivência e a condição sociocultural dos educandos, orientando o professor a apreender a realidade deles e a preparar-se para uma efetiva interlocução. Desta forma, se estabelece uma lista de assuntos de interesses dos alunos, depois ordenada de acordo com os conceitos da ementa formal da disciplina. O aprendizado é então conduzido numa sequência que favorece a construção conceitual que, na medida do possível, se inicia pelo "como funciona" e prossegue por níveis crescentes de abstração. O GREF produziu livros de Mecânica, Física Térmica e Ótica e Eletromagnetismo utilizados na preparação de professores do ensino médio para adotarem aquela metodologia para cada uma das disciplinas.

Deste modo, se a opção do GREF para a abordagem de conhecimentos físicos na educação escolar não é estruturada por temas geradores obtidos por uma investigação temática e a consequente redução temática (DELIZOICOV, 2008; FREIRE, 1975), conforme dinâmica adotada nos projetos da Guiné Bissau, do Rio Grande do Norte e do município de São Paulo, mantém, contudo, um dos princípios fundamentais da proposição freireana no que diz respeito à dialogicidade a ser efetivada em torno de situações sobre as quais os alunos se expressam e que permitem introduzir conceituação de física. Foi a partir desta perspectiva concebida pelo GREF que os autores do livro "Física" inseriram, em alguns tópicos do livro, atividades propostas e desenvolvidas pelo grupo, ainda na sua versão preliminar. Os autores assim se referem à relação estabelecida:

Desde 1984, o Subprograma Educação para a Ciência (SPEC) vem financiando projetos de ensino de Ciências em todo o território nacional. Destes, destacamos alguns mais pertinentes ao ensino de Física. Ressaltamos, aqui, o projeto elaborado pelo Grupo de Reelaboração do Ensino de Física (GREF), coordenado por uma equipe de professores do Instituto de Física da USP. [...]. Destacamos especialmente este projeto devido à identificação entre a abordagem nele proposta e a que estamos sugerindo neste trabalho.” (DELIZOICOV; ANGOTTTI, 1990a, p. 32)

Conforme pode ser notado no livro "Física", são constantes e sistemáticas as referências ao GREF, especialmente no item Leitura Recomendada. Há tópicos nos quais há a reprodução de textos originalmente elaborados na versão preliminar, pela equipe GREF, particularmente os que se apresentam no segundo momento pedagógico, Organização do Conhecimento, e no terceiro, Aplicação do Conhecimento (DELIZOICOV; ANGOTTI, 1990a). 
Portanto, por meio da circulação de ideias (FLECK, 1986, 2010) ocorrida e caracterizada tanto no depoimento de Menezes (1996) como a contida no livro, pode ser considerado outro aspecto que influiu na transformação pela qual passaram os $3 \mathrm{MP}$, desde a sua construção e uso nos três projetos iniciais, fundamentados em Freire, até a sua proposição no livro "Física". Destaca-se, contudo, uma sintonia mais próxima entre as concepções educacionais compartilhadas pelos membros desses dois coletivos, o GREF e os autores do livro. Estaríamos frente a uma situação que poderia ser caracterizada como dois coletivos de pensamento que compartilham matizes de um mesmo estilo de pensamento (FLECK, 1986, 2010). Não obstante, teríamos, também na perspectiva fleckiana, dois coletivos que compartilham distintos estilos de pensamento se forem comparados ao grupo de educadores que compartilham o ideário da pedagogia crítico-social dos conteúdos com o grupo que introduziu a perspectiva freireana no ensino escolar de física (DELIZOICOV, 2008).

\section{Considerações finais}

Foi possível perceber a existência de três grupos de educadores com premissas relativamente distintas e que estabeleceram interação no que diz respeito à produção do livro "Física". Se, por um lado, essa interação propiciou modificações na abordagem e uso dos 3MP, por outro, possibilitou que os autores do livro em pauta fizessem considerações iniciais sobre aspectos relativos a temas. Como se observou, o livro "Física" foi estruturado para desenvolver a programação dos conteúdos de física para o Ensino Médio, tendo como tema central "Produção, distribuição e consumo de energia elétrica", o que representou uma novidade, em 1990, em termos da organização e desenvolvimento de um programa de física, que, tradicionalmente, se estrutura a partir das partes em que a Física é dividida, tal como Mecânica, Eletricidade, Óptica. Além disso, introduziu a necessidade de se abordar, também, conceituação relativa à Física Moderna como condição para uma compreensão mais consistente do tema que estruturou a introdução de conceitos da física ao longo do livro. Conforme se destacou, a conceituação produzida pela Física Moderna ainda não constava como um conteúdo a ser desenvolvido no Ensino Médio, como registra, dentre outros, o trabalho de Terrazzan (1994), situação que passa a ser bastante criticada, sobretudo na última década do século XX, inclusive, porque estaríamos próximos da entrada no século XXI e a física escolar, ensinada nas escolas de Ensino Médio, ainda se limitava a alguns dos conteúdos relativos às teorias da Física produzidas apenas até o século XIX.

Ao longo dos anos, os 3MP foram sendo revistos e extrapolaram sua utilização inicial, tornando-se um parâmetro para o processo como um todo, fundamentalmente pelo aspecto dinâmico. Assim, pode-se, hoje, destacar mais uma utilização não conjecturada inicialmente, que é a elaboração de material didático para cursos de graduação à distância (livro do aluno) ${ }^{9}$ e a utilização como estruturadores/organizadores das discussões em eventos ${ }^{10}$, além da proposição e publicação dos livros "Física" e "Metodologia do ensino de ciências". Diante dessa análise, percebe-se que a participação do estudante e o seu cotidiano assumem um papel de destaque na prática educativa que utiliza os 3MP, proporcionando, à educação, um avanço no que se refere ao ensino tradicional. 
Dentre as características da dinâmica dos 3MP, está a apresentação dos assuntos não como fatos a memorizar, mas como problemas a serem resolvidos, propostos a partir da experiência de vida dos educandos, possibilitando que, durante o período de escolarização, tais problemas sejam compreendidos por meio de conhecimentos que os alunos ainda não possuem, quais sejam aqueles universais, tal como os das teorias da física. Ao se problematizar, de forma dialógica, pretende-se que os conceitos sejam integrados à vida e ao pensamento do educando. Ao invés da memorização de informações sobre Química, Física ou Biologia, ocorre o enfrentamento dos problemas vivenciados. Contudo, conforme analisa Delizoicov (2008), um emprego estático e mecânico dos 3MP pode, simplesmente, manter uma perspectiva para o ensino de física por meio de uma estratégia didática que apenas usa o primeiro momento pedagógico como pretexto para introduzir, no Segundo Momento, conteúdos tradicionalmente abordados sem um compromisso da problematização e da dialogicidade, que são características essenciais e estão na gênese da proposta dos 3MP. O par de categorias problematização e dialogicidade são os elementos que, na argumentação de Delizoicov (2001), desafiam os professores a estabelecer uma prática docente que problematiza conhecimentos, tanto os prévios dos alunos quanto os contidos nas teorias científicas, em sintonia com as considerações de Bachelard (1977, 1996), de modo que temas significativos e contraditórios possam ser melhor compreendidos no sentido de alguma atuação transformadora.

Por sua vez, merece ser destacado que a circulação de ideias, conhecimentos e práticas oriundas das interações entre o coletivo de educadores freireanos que atuou nos projetos da Guiné Bissau, São Paulo do Potengi e Secretaria Municipal de Educação de São Paulo, com o coletivo que coordenou o GREF, também teve seus desdobramentos. Se o GREF influenciou o livro "Física" na proposição de práticas pedagógicas para a sala de aula, com seus reflexos na transformação ocorrida nos $3 \mathrm{MP}$, a proposta de uma abordagem temática enquanto estruturadora da programação de conteúdos escolares parece ter influenciado membros da equipe GREF.

Assim, Menezes, Kawamura e Hosoume, da equipe de coordenação do GREF, participaram da elaboração dos parâmetros curriculares nacionais (PCN) do Ensino Médio relativos à natureza, matemática e suas tecnologias (BRASIL, 2000).

Esses parâmetros, além de terem como uma das referências as categorias contextualização e interdisciplinaridade, explicitam que a organização curricular deve ter como referência temas estruturadores e unidades temáticas (BRASIL, 2000, 2002, 2006). Contudo, deve se ter em conta que a designação temas é polissêmica e tem distintos significados, e não somente aquele que se entende como tema gerador. Um bom exemplo dessa polissemia pode ser contemplada nos Parâmetros Curriculares Nacionais - Ensino Fundamental (BRASIL, 1998), que propõem uma estruturação curricular na perspectiva de uma abordagem temática a partir de Temas Transversais.

Evidentemente, a elaboração dos PCN - Ensino Médio e PCN+ envolveu equipes de especialistas de várias áreas e, portanto, foram plurais as influências mútuas que podem ter se originado nas distintas circulações intercoletivas que certamente ocorreram. Deste modo,

\footnotetext{
${ }^{9}$ Cf. Disciplina Didática Geral do curso de Licenciatura em Física a Distância da Universidade Federal de Santa Catarina (UFSC).

${ }^{10} 9^{\circ}$ Fórum de Estudos: Leituras de Paulo Freire, ocorrido em maio de 2007, na cidade do Rio Grande/RS.
} 
não se trata de conjecturar determinações, mas, sim, um processo dinâmico, coletivamente gestado, que torna praticamente impossível atribuir autorias, ou gêneses, da produção de ideias e de proposição de práticas educativas, a determinados indivíduos, ou, mesmo, a algum determinado coletivo. Este aspecto ressaltado por Fleck (1986, 2010), relativamente à produção de conhecimentos por equipes, destacado e analisado em vários trechos da sua obra, precisa estar presente. Não obstante, é pertinente considerar que a concepção de organização curricular para o Ensino Médio, numa perspectiva de abordagem temática como a assumida e proposta pelos PCN e PCN+ é inédita, no Brasil, enquanto proposta oficial do Estado. Talvez, por isso, ainda estejamos apenas iniciando a sua implementação, e, possivelmente, com dificuldades, uma vez que ela representa uma lógica curricular radicalmente distinta da lógica contida na abordagem conceitual, que tem como referência exclusiva apenas a estrutura conceitual de disciplinas, e que, histórica e hegemonicamente, tem balizado professores e formadores de professores para organizar currículos e programas de ensino.

\section{Referências}

ANGOTTI, J. A. P. Solução alternativa para a formação de professores de ciências: um projeto educacional desenvolvido na Guiné-Bissau. 1982. 189 f. Dissertação (Mestrado) - Universidade de São Paulo, São Paulo, 1982.

. Conceitos unificadores e ensino de física. Revista Brasileira de Ensino de Física, São Paulo, v. 15, n. 4, p. 191-198, 1994.

BACHELARD, G. A formação do espírito científico. Rio de Janeiro: Contraponto, 1996.

. O racionalismo aplicado. Rio de Janeiro: Zahar, 1977.

BELTRAN, N. O.; CISCATO, C. A. M. Química. São Paulo: Cortez, 1991.

BRASIL. Ministério da Educação. Interdisciplinaridade no município de São Paulo. Brasília: INEP: MEC, 1994. (Série Inovações educacionais).

. PCN+ orientações educacionais complementares aos parâmetros curriculares

nacionais: ciências da natureza, matemática e suas tecnologias. Brasília: MEC: SEMT, 2002.

- Ministério da Educação. Secretaria de Educação Básica. Orientações curriculares para o

ensino médio: ciências da natureza, matemática e suas tecnologias. Brasília: MEC, 2006.

. Ministério da Educação. Secretaria de Educação Fundamental. Parâmetros curriculares

nacionais: terceiro e quarto ciclos do ensino fundamental. Brasília: MEC: SEF, 1998.

. Ministério da Educação. Secretaria de Educação Média e Tecnológica. Parâmetros

curriculares nacionais ensino médio, bases legais: linguagens, códigos e suas tecnologias. Brasília: MEC: SEMTEC, 2000. 
DA ROS, M. A. Fleck e os estilos de pensamento em saúde pública: um estudo da produção científica da FSP/USP e ENSP/FIOCRUZ entre 1948 e 1994. 2000. 207 f. Tese (Doutorado em Educação) - Universidade Federal de Santa Catarina, Florianópolis, 2000.

DELIZOICOV, D. Concepção problematizadora do ensino de ciências na educação formal: relato e análise de uma prática educacional na Guiné Bissau. 1982. 227 f. Dissertação (Mestrado) Universidade de São Paulo, São Paulo, 1982.

. Conhecimento, tensões e transições. 1991. 214 f. Tese (Doutorado) - Faculdade de Educação, Universidade de São Paulo, São Paulo, 1991.

. La educación en ciencias y la perspectiva de Paulo Freire. Alexandria: revista de educação em ciência e tecnologia, Florianópolis, v. 1, n. 2, p. 37-62, 2008.

. Ensino de física e a concepção freireana de educação. Revista de Ensino de Física, São Paulo, v. 5, n. 2, p. 85-98, 1983.

. Uma experiência em ensino de ciência na Guiné Bissau: depoimento. Revista de Ensino de Física, São Paulo, v. 2, n. 4, p. 57-72, 1980.

. Fleck e a epistemologia pós empirismo lógico. In: FÁVERO, M. H.; CUNHA, C. da.

(Org.). Psicologia do conhecimento: diálogo entre as ciências e a cidadania. Brasília: Unesco, 2009. p. 233-258.

. Problemas e problematizações. In: PIETROCOLA, M. (Org.). Ensino de Física: conteúdo, metodologia e epistemologia numa concepção integradora. Florianópolis: Ed. da UFSC, 2001. p. $125-150$.

DELIZOICOV, D., et al. Sociogênese do conhecimento e pesquisa em ensino: contribuições a partir do referencial fleckiano. Caderno Brasileiro de Ensino de Física, Florianópolis, v. 19, p. 52-69, 2002. (Número especial).

DELIZOICOV, D.; ANGOTTI, J. A.; PERNAMBUCO, M. M. Ensino de ciências: fundamentos e métodos. São Paulo: Cortez, 2002.

DELIZOICOV, D.; ANGOTTT, J. A. Física. São Paulo: Cortez, 1990a.

. Metodologia do ensino de ciências. São Paulo: Cortez, 1990b.

DELIZOICOV, N. C. Ensino do sistema sangüíneo humano: a dimensão histórico-epistemológica. In: SILVA, C. C. Estudos de história e filosofia das ciências: subsídios para aplicação no ensino. São Paulo: Livraria da Física, 2006. p. 265-286.

DELIZOICOV, N. C.; CARNEIRO, M. H.; DELIZOICOV, D. O Movimento do sangue no corpo humano: do contexto da produção do conhecimento para o de seu ensino. Ciência \& Educação, Bauru, v. 10, n. 3, p. 443-460, 2004.

FLECK, L. Gênese e desenvolvimento de um fato científico. Belo Horizonte: Fabrefactum, 2010.

. La génesis y el desarrollo de un hecho científico. Madrid: Alianza, 1986.

FREIRE, P. Pedagogia do oprimido. Rio de Janeiro: Paz e Terra, 1975.

. A educação na cidade. São Paulo: Cortez, 2006.

GONÇALVES, F. P.; MARQUES, C. A.; DELIZOICOV, D. O desenvolvimento profissional dos formadores de professores de química: contribuições epistemológicas. Revista Brasileira de Pesquisa em Educação em Ciências, Belo Horizonte, v. 7, n. 3, p. 51-67, 2007. 
Os três momentos pedagógicos e o contexto...

GRUPO DE REELABORAÇÃO DO ENSINO DE FÍSICA. Física 1: mecânica. São Paulo: Edusp, 1990.

Física 2: física térmica e óptica. São Paulo: Edusp, 1992.

Física 3: eletromagnetismo. São Paulo: Edusp, 1995.

LEITE, R. C. M.; FERRARI, N.; DELIZOICOV, D. A história das leis de Mendel na perspectiva fleckiana. Revista Brasileira de Pesquisa em Educação em Ciências, Belo Horizonte, v. 1, n. 2, p. 97-108, 2001.

LIBÂNEO, J. C. Democratização da escola pública. São Paulo: Loyola, 1987.

LORENZETTI, L. Estilos de pensamentos em educação ambiental: um estudo a partir das dissertações e teses. 2008. 407 f. Tese (Doutorado em Educação Científica e Tecnológica) Universidade Federal de Santa Catarina, Florianópolis, 2008.

LÖWY, I. The polish school of philosophy of medicine: from Tytus Chalubinski (1820-1889) to Ludwik Fleck (1896-1961). Dordrecht: Kluwer, 1990.

MENEZES, L. C. Crise, cosmos, vida humana: física para uma educação humanista. 1988. 266 f. Tese (Livre Docência) - Universidade de São Paulo, São Paulo, 1988.

. Paulo Freire e os físicos. In: GADOTTI, M. (Org.). Paulo Freire: uma biobibliografia. São Paulo: Cortez: Instituto Paulo Freire, 1996. p. 638-641.

MOREIRA, A. F. B. Propostas curriculares alternativas: limites e avanços. Educação \& Sociedade, Campinas, v. 21, n. 73, p. 109-138, 2000.

MUENCHEN, C. A disseminação dos três momentos pedagógicos: um estudo sobre práticas docentes na região de Santa Maria/RS. 2010. 273 f. Tese (Doutorado em Educação Científica e Tecnológica) - Centro de Ciências em Educação, Universidade Federal de Santa Catarina, Florianópolis, 2010.

MUENCHEN, C.; DELIZOICOV, D. Pesquisas em educação em ciências na região de Santa Maria/RS: algumas características. In: ENCONTRO NACIONAL DE PESQUISA EM EDUCAÇÃO EM CIÊNCIAS, 7., 2009, Florianópolis. Atas... Disponível em: < http://posgrad.fae. ufmg.br/posgrad/viienpec/pdfs/232.pdf >. Acesso em: 18 jul. 2014.

PERNAMBUCO, M. M. C. A. Ensino de ciências a partir de problemas da comunidade. 1981. Dissertação (Mestrado) - Universidade de São Paulo, São Paulo, 1981.

PERNAMBUCO, M. M. C. et al. Projeto ensino de ciências a partir de problemas da comunidade. In: SEMINÁRIO CIÊNCIA INTEGRADA E/OU INTEGRAÇÃO ENTRE AS CIÊNCIAS: TEORIA E PRÁTICA, Rio de Janeiro, 1988. Atas... Rio de Janeiro: Editora UFRJ, 1988.

PIMENTA, S. G.; GONÇALVES, C. L. Revendo o ensino de $2^{\circ}$ grau: propondo a formação de professores. São Paulo: Cortez, 1990.

PIMENTA, S. G.; LIBÂNEO, J. C. Apresentação da coleção. In: DELIZOICOV, D.; ANGOTTI, J. A. P. Metodologia do ensino de ciências. São Paulo: Cortez, 1990. 9-12.

PONTUSCHKA, N. (Org.). Ousadia no diálogo: interdisciplinaridade na escola pública. São Paulo: Loyola, 1993.

SÃO PAULO. Secretaria Municipal de Educação. Cadernos de formação 01, 02 e 03. São Paulo, SME, 1990. (Série Ação pedagógica na escola pela via da interdisciplinaridade). 
Visões de área. São Paulo: SME, 1992.

SCHEID, N. M. J.; FERRARI, N.; DELIZOICOV, D. A construção coletiva do conhecimento científico sobre a estrutura do DNA. Ciência \& Educação, Bauru, v. 11, n. 2, p. 223-233, 2005.

SLONGO, I. I. P.; DELIZOICOV, D. Teses e dissertações em ensino de biologia: uma análise histórico-epistemológica. Investigações em Ensino de Ciências, Porto Alegre, v. 15, n. 2, p. 275-296, 2010.

SONCINI, M. I.; CASTILHO JR., M. Biologia. São Paulo: Cortez, 1991.

TERRAZZAN, E. A. Perspectivas para a inserção da física moderna na escola média. 1994.

Tese (Doutorado em Educação) - Universidade de São Paulo, São Paulo,1994.

TORRES, C. A.; O’ CADIZ, M. P.; WONG, P. L. Educação e democracia: a práxis de Paulo Freire em São Paulo. São Paulo: Cortez: Instituto Paulo Freire, 2002.

Artigo recebido em 28/09/13. Aceito em 07/01/14. 